\title{
Aos passos com b-boys: individuações e reflexividades de uma prática
}

LEANDRO ROGÉRIO PINHEIRO Universidade Federal do Rio Grande do Sul, Porto Alegre, RS, Brasil

RESUMO

Este ensaio resulta de interlocuções com ativistas do hip-hop e atenta aos debates sobre os processos de individuação vivenciados nas relações sociais contemporâneas. Propõe-se a problematizar como a prática de breakdance tem contribuído à individuação identitária de dançarinos do Restinga Crew, grupo atuante em Porto Alegre, Rio Grande do Sul, Brasil. As proposições de Alberto Melucci e de Danilo Martuccelli são as principais referências, e a pesquisa foi efetivada nos anos de 2013 e 2014, mediante observação in loco e realização de entrevistas narrativas. O texto destaca as dinâmicas reflexivas produzidas pela crew, considerando as possibilidades de singularização individual gestadas aí, em articulação ao reconhecimento dos pares e à pertença coletiva. Argumenta-se que os desafios experenciados nesse sentido ambientaram produção de capitais culturais e sustentavam inserções em outros espaços sociais.

PALAVRAS-CHAVE

individuação; reflexividades; juventudes; breakdance; hip-hop. 


\title{
IN STEP WITH B-BOYS: INDIVIDUATION AND REFLEXIVITIES FROM A PRACTICE
}

\begin{abstract}
Attentive to the debates on individuation process lived in the contemporary social relations, this essay has resulted from dialogues with hip-hop's activists. It aims to discuss how breakdance practice has contributed to identity individuation of dancers of Restinga Crew, group from Porto Alegre, Rio Grande do Sul, Brazil. Propositions by Alberto Melucci and Danilo Martuccelli are the main references and the research was conducted in 2013 and 2014, by in loco observation and narrative interviews. The text emphasizes the reflexive dynamics produced by the crew regarding possibilities of individual singularization built in relation with peer recognition and the collective belonging. In this sense, it analyses the challenges experienced as ambient to production of cultural capital and as support to get integration in others social spaces.
\end{abstract}

KEYWORDS

individuation; reflexivities; young people, breakdance; hip-hop.

\section{A PASOS CON B-BOYS: INDIVIDUACIONES Y REFLEXIVIDADES DE UNA PRÁCTICA}

\section{RESUMEN}

Fijándose en los debates sobre procesos de individuación vividos en las relaciones sociales contemporáneas, este ensayo resulta de interlocuciones con activistas del hip-hop. Problematiza cómo la práctica de breakdance ha contribuido a la individuación identitaria de bailarines del Restinga Crew, grupo de Porto Alegre, Rio Grande do Sul, Brasil. Proposiciones de Alberto Melucci y de Danilo Martuccelli son los principales referentes, y la investigación fue realizada en 2013 y 2014, mediante observación in loco y realización de entrevistas narrativas. El texto señala las dinámicas reflexivas producidas por el grupo y considera relaciones entre estas y las posibilidades de singularización individual concretadas en articulación al reconocimiento de los pares y a la pertenencia colectiva. Argumenta que los desafíos vividos en este sentido ambientaron producción de capitales culturales y aportaron inserciones en otros espacios sociales.

individuación; reflexividades; juventudes; breakdance; hip-hop. 


\section{INTRODUÇÃO}

Os estudos sobre as juventudes vêm enfatizando as singularidades da condição juvenil contemporânea, destacando suas aproximações às produções artísticas e simbólicas na configuração de laços de sociabilidade e pertencimento, assim como na vivência de processos de socialização tensionados pela pluralidade de experiências. Nesse contexto, merecem lugar de destaque questionamentos sobre as táticas desenvolvidas pelos jovens na construção de seus percursos e no deslindar de suas expectativas.

Sensíveis a esse cenário, as problematizações trazidas neste texto resultam de pesquisas iniciadas em 2011, em aproximação às práticas do hiph-hop em Porto Alegre, Rio Grande do Sul. Era seguido um diálogo com jovens ativistas desse movimento quando se deu o contato com o Restinga Crew, um grupo de dançarinos de break ${ }^{1}$ que mantinha atividades há mais de dez anos, um fato incomum entre os coletivos identificados durante incursões a bairros de periferia da cidade.

A pesquisa se orientava às produções identitárias e, no curso das interlocuções com os b-boys do grupo, procurou-se conhecer mais da relação deles com a prática de dança e com a "cultura $h i p-h o p "$ ". Nos treinos organizados pela crew, chamava a atenção a maneira significativamente autônoma como cada um conduzia seus exercícios e, também, a recorrente tônica na composição de estilos individuais verbalizada pelos dançarinos, sem que isso fragilizasse a duradoura pertença destes ao coletivo.

Algumas das contribuições de Martuccelli (2007) e de Melucci (2001;2004) auxiliaram no desenho de argumentos acerca do que fora presenciado com os dançarinos, de forma que este ensaio se configura um exercício de compreensão de processos de identização, dirigidos mais enfaticamente ao âmbito das individuações. Assim, o presente trabalho dispõe uma análise sobre itinerários produzidos por jovens em contextos de periferia, entendendo que uma aproximação às suas dinâmicas de identização e reflexividade pode trazer provocações às práticas educativas, especialmente se reconhecidas aí experiências de produção de saberes, sentidos e condições para existência.

Houve aqui um cuidado em organizar a escrita a fim de apresentar o contexto analítico e os referentes teórico-metodológicos que a animam. Então, são

1 O break é considerado um tipo de dança de rua. Formou-se nos anos 1970 com outros elementos da "cultura" hip-hop em bairros de maioria populacional negra e caribenha de Nova Iorque. De início, compunham gestualidades que reportavam a circunstâncias de batalha, numa alusão à Guerra do Vietnã, destino de muitos jovens afrodescendentes e latinos do período (Oliveira, 2004). Hoje, o estilo agrega dançarinos em campeonatos e atividades recreativas em diversos espaços urbanos. Entre os interlocutores desta pesquisa, era caracterizada especialmente pela flexibilidade na composição das sequências coreográficas, integrando interpretações de acontecimentos cotidianos, passos de outras danças etc.

2 É utilizada a expressão "cultura hip-hop" entre aspas com o intuito de sinalizar a apropriação de termo utilizado pelos interlocutores desta pesquisa. Assim, também pretende-se salientar que o uso da palavra "cultura" não tem o objetivo de referir os conteúdos que lhe são atribuídos em leituras acadêmicas. 
analisadas as dinâmicas reflexivas construídas nas atividades da creww, discutindo suas potencialidades cotidianas na singularização de performances e individualidades. Por fim, tem-se a apresentação dos itinerários biográficos de dois jovens integrantes do grupo, tomados como casos para narrar processos de individuação desde a articulação desses com o break e o hip-hop.

\section{CONTEXTO E REFERENTES}

Individuação é a tendência cultural que enfatiza os projetos do indivíduo como princípio orientador de seu comportamento. Individuação não é individualismo, pois o projeto do indivíduo pode ser adaptado à ação coletiva e a ideais comuns, como preservar o meio ambiente ou criar uma comunidade, enquanto o individualismo faz do bem-estar do indivíduo o principal objetivo de seu projeto particular. (Castells, 2013, p. 168)

A perspectiva apresentada por Castells (2013) sinaliza para a existência de contextos socioculturais cuja dinâmica organizativa propicia que os sujeitos construam seus processos de socialização. Em seus argumentos, o autor contempla especialmente a ação de movimentos sociais e os efeitos da gestação de redes sociais ancoradas em tecnologias de comunicação e informação, a conformar trânsitos que já não dependem exclusivamente da ação de instituições sociais. Nesse sentido, nosso leitor é convidado a observar que a constituição de itinerários biográficos sofre alterações nas relações sociais contemporâneas.

Coetâneo, os rituais de passagem considerados indicadores da transição à vida adulta (estabilidade profissional, conjugalidade, residência autônoma, filhos etc. - em certa naturalização de referentes sociais produzidos no pós-guerra europeu) são adiados, dessincronizados e/ou revertidos hoje em dia (Pappámikail, 2012), borrando as fronteiras do que supúnhamos como fases de vida e, ademais, contribuindo para a diversificação dos rumos possíveis aos percursos individuais.

No caso europeu, novas dinâmicas dos sistemas produtivos e laborais levaram a uma ampliação do tempo dedicado aos estudos e ao adiamento do ingresso de parte dos jovens ao mundo do trabalho, prolongando o período compreendido como juventude. Já no Brasil, observa-se um "rearranjo" da sequência transicional, no qual a ampliação da escolarização convive com outros eventos considerados marcadores de transição para a vida adulta, como a maternidade/paternidade e a inserção laboral precoce, realizada antes (e/ou em detrimento) da conclusão da educação básica (Camarano, 2006).

Podemos somar a isso dois outros fatores, indicados por Vieira (2012). Primeiramente, a inflexão das representações de infância e juventude na atualidade, tendendo a reconhecer a crianças e jovens a condição de indivíduos com autonomia e que merecem ter voz, intensificando a experiência de nossa herança da modernidade. E, potencializando o primeiro, a diversificação de contextos socializadores - com destaque aos grupos de pares - que interpõem a neces- 
sidade de que os sujeitos gerenciem e elaborem a pluralidade em seus percursos biográficos. Este último, uma constatação trazida também por Melucci (2004) em O jogo do eu, quando assinala a característica múltipla, processual e autorreflexiva das identidades hoje, gestadas em ambientes urbanos de alta diferenciação e intensos apelos informacionais.

Os sistemas contemporâneos colocam à disposição dos indivíduos recursos simbólicos que estendem o seu potencial de individualização, isto é, de autonomia e de auto-realização: os indivíduos experimentam a capacidade de definir e controlar o que são e o que fazem, por meio da generalização dos processos de instrução, da difusão da participação política e dos direitos de cidadania, da importância atribuída às redes organizativas e comunicativas. (Melucci, 2001, p. 72)

Sinalizando para vivência de cotidianos crescentemente urbanizados e codificados socialmente, Melucci $(2001 ; 2004)$ considera que nossas necessidades (e os sinais da falta que elas condensam) tendem a se orientar para objetos constituídos por forte conotação simbólica, resultantes de nossas construções sociais ${ }^{3}$. Esse seria também o contexto de reconhecimento da identidade como produto social, lançada historicamente à dessacralização dos fundamentos metassociais e à diversificação das bases de identificação (no consumo, nos apelos informacionais, nas redes sociais de pertença etc.). Assim, o autor procura enfatizar que, para além de uma situação supostamente estática de delimitação de atribuições, a identidade configura-se como um processo no qual a reflexividade tende a ser intensificada. Mencionando que talvez fosse mais adequado falarmos de "identização", ele caracteriza a identidade mais como ação do que como uma situação; além de um conjunto de atribuições socialmente produzidas, uma capacidade reflexiva e de ação construídas a partir dessas.

Poder-se-ia definir identidade como a capacidade reflexiva de produzir consciência da ação (isto é, representação simbólica da mesma) além dos seus conteúdos específicos. A identidade transforma-se em reflexividade formal, capacidade simbólica, reconhecimento da produção de sentido no agir, no interior dos limites colocados em um dado momento, pelo ambiente e pela estrutura biológica. (Melucci, 2001, p. 89)

Lash (2012) lembra, contudo, que é necessário reconhecer as formas pelas quais aparatos e recursos culturais modernos chegam até o cotidiano dos

3 O trecho da sequência ilustra o que se busca referir: "Não temos mais simplesmente sede ou fome, tampouco necessidade de nos vestir; a falta que sentimos já orientada para objetos específicos, construídos simbolicamente pela informação, pelo mercado, pela comunicação publicitária e pelas redes sociais às quais pertencemos. Assim, temos sede de $\mathrm{A}$, podemos vestir somente $\mathrm{B}$, no café da manhã desejamos $\mathrm{C}$; definimos, pois, a falta conforme os códigos específicos do campo cultural cotidiano ao qual pertencemos e no qual acontece a comunicação.” (Melucci, 2004, p. 40). 
indivíduos, para então observarmos as possibilidades e formas da reflexividade ${ }^{4}$. As incursões em bairros de periferia, contextos em que a presença da institucionalidade moderna é tensionada pela precariedade dos acessos e pela presença insuficiente do Estado, interpõem questões sobre as formas de apropriação da ambiência reflexiva contemporânea.

Eis que as proposições de Martuccelli (2007) acerca da sociologia do indivíduo podem ser provocantes nesse sentido, apoiando uma aproximação contextualizada aos percursos biográficos. Consonante aos argumentos anteriores, o autor salienta que as relações sociais contemporâneas instigam experiências diversas, contribuindo para que estas se particularizem mesmo quando as pessoas ocupam posições sociais assemelhadas. Sua interpretação orienta-se ao processo de singularização estruturalmente produzido na modernidade e propõe operadores analíticos para a compreensão das formas pelas quais os indivíduos se constituem na relação com aspectos que perpassam a socialização na coletividade: uma relação que concerne à produção de identificação, mas que, para esse autor, precisa ser problematizada aquém e além da identidade.

Martuccelli (2007) apresenta a noção de "prova" como artifício para compreensão dos processos de individuação, destacando os desafios sócio-históricos que os indivíduos são impelidos a enfrentar (conforme as condições sociais em que se encontram) e que podem ser vivenciados singularmente no produzir-se como sujeito. Tomemos uma citação do autor:

Las pruebas tienen cuatro grandes características. En primer lugar, son indisociables de un relato que les asigna a los atores, individuales o colectivos, un papel mayor en la comprensión de los fenómenos sociales. En seguida, las pruebas hacen referencia a las capacidades que tienen un actor para afrontar las prescripciones e procesos difíciles a los cuales está sometido. En tercer lugar, toda prueba aparece como un examen, en realidad, como un mecanismo de selección a través del cual, en función de sus éxitos o fracasos, los actores forjan sus exis-

4 Nos limites deste texto, não teria como aprofundar as problematizações sobre a "modernização reflexiva", que Lash (2012) compartilha com Ulrich Beck e Anthony Giddens, mas cabe situar a especificidade de seus argumentos. A reflexividade nesta perspectiva associa-se à condição de risco e ambivalência gestada pelo eclipsar das "certezas" da modernidade. Nos termos de Beck (2012), seria uma espécie de autoconfronto com os dilemas interpostos por fatores estruturais historicamente produzidos como, por exemplo, a crise ambiental ou a reconfiguração da posição das mulheres no mercado de trabalho e na família. Não só reflexão; o vivenciar de questionamentos e escolhas em campos em que, antes, assentava-se a tradição. Nesse contexto, Lash acrescenta que os saberes e os apelos reflexivos se disseminam não somente por elaborações conceituais mas também por dinâmicas miméticas, "iconicamente por meio da semelhança” (Lash, 2012, p. 212). Dessa maneira, ressalta que a reflexividade aconteceria também no acesso a artefatos culturais (artísticos, imagéticos: filmes, programas de TV etc.), com os quais podemos refletir-nos e/ou dos quais podemos nos apropriar, na forma de uma "reflexividade estética". Entretanto, quando chegamos à "apropriação" podemos referir também, com Lash, uma "reflexividade hermenêutica", que significa participação em grupos de partilha e reapropriação. 
tencias. Por último, las pruebas son inseparables de un conjunto de grandes desafíos estructurales a los que los individuos están obligados a responder y que difieren en función de las sociedades y de los períodos históricos. (Martuccelli, 2007, p. 125)

A tal conceito, o autor associa também a noção de "suporte" para falar das relações que amparam os indivíduos no enfretamento de seus desafios existenciais. Aí, podemos situar laços de reciprocidade, redes de amizade e sociabilidade ou, então, a articulação a aparatos institucionais que garantam e/ou promovam condições para que os sujeitos efetivem seus projetos e/ou logrem seguir em disputa.

Ambas as noções, "prova" e "suporte", foram assumidas como uma inspiração para interpretar as práticas e os itinerários dos b-boys do Restinga Crew, observando condições materiais e culturais de sua existência e os caminhos trilhados para legitimação de suas escolhas e projetos individuais. Vejamos, pois, como foi conduzida a experiência em campo na consecução do propósito deste estudo.

\section{EM CAMPO}

A interlocução com o Restinga Crew teve início quando o autor do presente estudo passou a acompanhar os ensaios que o grupo realizava em um ginásio municipal. Suas incursões foram iniciaram no segundo semestre de 2013, quando então era objetivado o registro em diário das impressões do autor sobre a forma como operavam na aprendizagem de passos de dança e a maneira como sociabilizavam e partilhavam saberes sobre o break ou outras práticas de que participavam. Assim, houve uma aproximação gradativa do entendimento da maneira como fruíam a música, mantinham laços de pertença à crew e ao hip-hop e singularizavam estilos.

Depois de seis meses de observação, incluindo aí o acompanhamento a apresentações do Restinga Crew em eventos da cidade, foram realizadas entrevistas narrativas com os dançarinos (Jovchelovitch, 2002), visando que elaborassem seus itinerários de vida, para que fosse possível conhecer suas interpretações sobre o lugar do break e da "cultura hip-hop" em suas trajetórias e também os desafios que consideravam marcantes nos percursos.

Após as entrevistas, foi consolidado um novo período de observação, de aproximadamente dois meses, no primeiro semestre de 2014 . As atividades realizadas pelos interlocutores eram regularmente acompanhadas quando estes não estavam com o grupo, dando destaque àquelas que lhes ocupavam por mais tempo (trabalho e estudo) e/ou tinham sido narradas como mais significativas.

Todos os registros em diário e as narrativas elaboradas pelos interlocutores foram analisados procurando problematizar as vivências de "provas" e "suportes" no sentido atribuído por Martuccelli (2007). Passagens narradas como marcantes foram analisadas como indiciadores de "êxitos" (ou "fracassos") no enfrentamento dos desafios que seus contextos sociais lhes interpunham e também como sinalizadores das disposições e redes de pertença que suportavam seus percursos. Leituras sobre as condições de vida em suas localidades e sobre as frentes de ação do hip-hop, assim como um olhar transversal sobre os vários percursos narrados, oportunizaram acurar a delimitação de desafios estruturais, situando aí também as práticas em breakdance. 
Em que pese a similaridade das posições sociais ocupadas pelos b-boys, o contraste das táticas no delinear de itinerários oportunizou que fossem ponderadas as nuances das buscas por distinção, interpretando suas narrativas pessoais como expressão de processos de individuação socialmente experienciados.

Passemos, pois, à exposição das atividades do grupo e, em seguida, às narrativas sobre os percursos biográficos dos interlocutores.

\section{SOBRE AS DINÂMICAS REFLEXIVAS: O GRUPO, OS ENSAIOS E A SINGULARIZAÇÃO}

No início dos anos 2000, a maior parte dos integrantes da atual formação da crew passou a frequentar o ginásio do Centro de Comunidade da Vila Restinga ${ }^{5}$ (CECORES) para acompanhar atividades de dança. Á época, Jukinha, b-boy que realizava oficinas de break naquele espaço, articulava suas aulas à formação de um grupo para apresentações em eventos (Rekziegel, 2004). O grupo passou a ensaiar naquele lugar e, gradativamente, a fazer apresentações em eventos. Inicialmente, a crew era formada apenas por jovens moradores da Restinga, mas, em razão da visibilidade obtida na cidade e também das redes de sociabilidade e trabalho de seus integrantes, passou a congregar dançarinos de diferentes bairros de periferia.

$\mathrm{Na}$ interlocução, o grupo tinha aproximadamente 10 anos de existência e, na medida de suas possibilidades financeiras, procurava garantir representação em campeonatos no estado ou no centro do país e, algumas vezes, protagonizava a organização de eventos no bairro e na cidade. Apesar da oscilação do número de integrantes, mantinha ensaios regulares três vezes por semana, à noite. Eram aproximadamente oito jovens, com idades entre 17 e 29 anos e, na maioria dos casos, com carreiras escolares fragmentadas ou interrompidas pela necessidade de trabalhar. Percebia-se, ademais, que entre aqueles com menos idade a escolarização era mais bem-sucedida, com vistas à conclusão do ensino médio.

Cada um dos integrantes já havia passado por diferentes desafios e adversidades. Os mais antigos na crew tiveram filhos na adolescência. Todos enfrentaram a necessidade de trabalhar precocemente em diferentes atividades precarizadas e acalentavam o desejo de melhorar suas condições de vida. $\mathrm{O}$ grupo seguia sem qualquer tipo de fomento institucional; costumava usar espaços públicos (escolas municipais ou mesmo o CECORES) para seus ensaios e a fruição de suas atividades fazia das praças e ruas um locus de ação.

Nesse cenário, os laços entre os membros da crew transcendiam os treinos e apresentações. Desde a convivência no grupo, formavam entre si

5 O bairro Restinga, localizado no extremo sul do município de Porto Alegre, foi criado por intervenção do poder público nos anos 1960. Resultou da remoção de famílias das chamadas "vilas de malocas", comunidades cujas habitações eram precárias com maioria de população negra. A localização de tais moradias era próxima ao centro da cidade, em área cobiçada pelo mercado imobiliário (Nunes, 1990). Apesar das conquistas dos moradores, ainda é uma das localidades mais empobrecidas e com mais altos índices de violência social, destacando-se o número de mortes de jovens (ObservaPoa, 2015). 
vínculos de amizade e reciprocidade que, recorrentemente, eram reafirmados em suas falas e em publicações de redes sociais. Costumeiramente, mencionavam que a crew era também sua "família"; muitas vezes, a participação em eventos de alguns era amparada por recursos do coletivo e, em outras situações, colaboravam com colegas de grupo, acolhendo-os por tempo indeterminado em suas casas.

As memórias evocadas pelos b-boys vinham acompanhadas da menção às condições de vida e da afirmação do enfrentamento às adversidades como motivo de distinção dos integrantes da crew. Quando narravam suas rotinas diárias, realçavam seus esforços para manter a qualidade de suas performances, a enunciar a necessidade de resistência e superação para se alcançar o desejado. Nesse sentido, afirmavam ser possível levar em conta as dificuldades experienciadas e também admitir ignorância sobre algo, mas não se admitia que o sujeito se eximisse de tentar e marcar uma posição. Aqui, a palavra "atitude" parecia ser signo desse discurso, e as incursões em campo indicavam que esse seria um traço corrente ao sistema simbólico do bip-hop, a exemplo do que afirma Pardue (2008).

Eis que tal discurso sinalizava também para critérios de ingresso no grupo. Os treinos eram abertos, mas o ingresso à crew passava pelo atendimento de requisitos. Foi relatado, a propósito, que haveria uma espécie de processo seletivo, que incluía demonstração de empenho nos treinos, disposição para acompanhar o grupo em eventos, permanência e regularidade de presença entre as atividades e vivência dos elementos da "cultura".

A gente cria uma prova; são 35 questões. Essas 35 questões são todas relacionadas com o Hip-Hop e os quatro elementos. Então, eu passo a prova pra eles; eles fazem a prova, me passam, eu corrijo até porque eles confiam em mim! Porque eu sou o que mais estudo deles. (Seco - Dez/2013)

A partir dessa configuração, embora se pudesse ter várias pessoas a partilhar saberes sobre passos de dança nos treinos, a formação do Restinga Crew em apresentações públicas mantinha um núcleo de participantes relativamente estável. Dos oito dançarinos que compunham a crew no período das interlocuções, cinco haviam ingressado à época de sua constituição, em 2003.

Todas as vezes que gente ia se apresentar a gente tinha que dizer o nome [...] "Fala o nome, fala onde tu mora". Já começava aquela palhaçada: "bah... fecha a porta que os caras da Restinga estão aqui. Guarda as bolsas!” Aí, a gente resolveu criar o Restinga Crew. (Henrique - Set/2013)

O nome da crew surgiu em decorrência das exibições fora da Restinga. Segundo contam, eram frequentes os comentários preconceituosos quando informavam a origem do grupo. Então, em rechaço à discriminação, decidiram colocar o bairro no nome do grupo, fazendo do estigma um emblema (Reguillo, 2012).E tal formulação parece compor com os modos de operar nas práticas em dança e arranjos relacionais que as constituem, tessituras essas aqui denominadas"dinâmicas reflexivas" e esboçadas na sequência. 


\section{DOS TREINOS AOS ENSAIOS}

Os treinos que faziam semanalmente no CECORES foram acompanhados. Costumavam chegar por volta das $19 \mathrm{~h}$ no ginásio. As atividades aconteciam em espaço contíguo a uma quadra poliesportiva, em local aberto e podiam ser acompanhadas por quem quisesse. Aqueles que desejavam aprender a dançar podiam se aproximar e participar. Os b-boys costumavam dar algumas orientações sobre movimentos básicos.

Henrique $^{6}$, liderança do grupo no que tange à organização das atividades, era o primeiro a chegar geralmente. Trazia consigo uma caixa de som e sua mochila, e logo dispunha os equipamentos em funcionamento. $\mathrm{O}$ som de músicas em alto volume tomava o espaço e, pouco a pouco, integravam-se os demais participantes. Cada pessoa que chegava cumprimentava os presentes um a um e, em um caso ou outro, conversavam e partilhavam acontecimentos do dia.

Em geral, percebia-se que os treinos tinham uma sequência e eram iniciados por alongamentos e aquecimentos. Em seguida, dedicavam-se a práticas individuais de realização e qualificação de passos, numa dinâmica persistente de tentativas e erros. Por fim, faziam uma roda de dança entre todos os presentes, quando, em um círculo, todos embalavam ao som da música e, paulatinamente, cada dançarino ia ao centro, fazia sua performance e provocava um colega para que também o fizesse.

Essa rotina era variável. Alguns resistiam a fazer alongamentos e aquecimentos e preferiam partir para o treino individual; a roda coletiva nem sempre acontecia, ou podia ser substituída por um momento de deliberação do grupo. A intensidade dos treinos podia variar conforme a temperatura, e o frio das noites de inverno no ginásio podia limitar a prática. Quando realizado plenamente, porém, o treino parecia compor uma estrutura análoga a das vivências do grupo em sua inserção no campo da dança de rua e, então, configurava-se como ensaio. Com isso pretende-se dizer que, ao estabelecer-se uma sequência que passava da prática individual a apresentações para o coletivo, refletia-se a organização de sua prática: períodos de preparação e a expectativa de apresentações públicas entre pares e para uma plateia, em um percurso permeado por fruição musical, sociabilidade e reconhecimento.

\section{A EXPERIÊNCIA DE FRUIÇÃO E SOCIABILIDADE}

Nesse aspecto, merece destaque a fruição vivenciada no curso dos ensaios. Frequentemente, os ritmos musicais pareciam cadenciar os exercícios dos b-boys e estimular a partilha de movimentos, as expectativas de êxito nos passos e as brincadeiras jocosas sobre os jeitos individuais.

Certa vez, foram contemplados Seco, ensaiando passos em frente ao espelho no ritmo de uma música e, em seguida, Heitor, acompanhando-o como se fosse uma coreografia. Chamaram outro garoto e seguiram os três. $\mathrm{O}$ som em volume alto

6 Serão citados nomes fictícios ao longo desta narrativa referindo a atuação de integrantes do grupo. Porém, nos limites deste texto, não poderão ser apresentados em detalhes apenas dois deles ao narrar seus itinerários biográficos. 
tomando o espaço parecia concentrá-los e conectar seus corpos que, em movimento cadenciado pelo ritmo, fluíam em gestos assemelhados e traziam ao observador a sensação de uma fruição empolgante, a ancorar a pulsação do tempo (Melucci, 2004) em uma experiência de partilha, integração e protagonismo.

Em outra ocasião, um torneio de dança era realizado mediante rachas entre $b$-boys durante a Semana Municipal do Hip-bop. Os dançarinos formavam duplas e participavam de embates, que acabavam por aludir simbolicamente a batalhas de gangues. Cada dupla fazia uma performance com pelo menos a sequência básica do break ${ }^{7}$ e, ao final, convidava os oponentes a atuarem fazendo-lhes uma provocação (um olhar, um gesto etc.), normalmente seguida de ovação ou risos do público.

Em um dos embates em que participavam integrantes do Restinga Crew, a disputa ficou bastante acirrada, entusiasmando quem assistia. Percebia-se que certa vibração transcendia a prática daqueles diretamente envolvidos e tomava os integrantes das crews que assistiam ali próximos, sobre o palco: as atuações dos b-boys eram acompanhadas também de provocações performáticas dos demais componentes dos grupos. Imbuídos da emoção da "batalha musicada", os movimentos expressavam a plasticidade de um espetáculo e evidenciavam, para além de conceber um público, conexão com uma ambiência e imersão em uma prática.

Aventa-se a hipótese, assim, de uma intensa vivência de sentir-se parte e socialmente potente, indiciando a incorporação de formas de expressão culturalmente valorizadas em uma sociedade permeada por espetáculos (Herschmann, 2005). A uma só vez, a fruição constituía memórias de partilha na sociabilidade e indicava tomadas de posição nas performances reflexivas da arte e do espetáculo.

\section{OS SABERES, AS DISPOSIÇÕES E A POSSIBILIDADE DE NAVEGAR}

Voltando agora aos treinos presenciados, pode-se atentar para detalhes relativos ao modo como os b-boys do Restinga Crew trabalhavam no desenvolvimento de sua prática.

\section{A MIMESE}

Embora estivessem todos no mesmo espaço e fruindo a mesma música, cada dançarino concentrava-se em um ou outro passo que estava tentando aprender. Eventualmente, trocavam olhares ou sinalizavam com poucas palavras a necessidade de alguma alteração de movimento a um colega. Não havia ali a figura de um educador que centralizasse as orientações. Os iniciantes recebiam orientações elementares, o estímulo para não se acanharem e, sobretudo, para persistirem. Depois, teriam igualmente que seguir repetindo e experimentando individualmente.

7 O break apresenta como sequência básica o toprock (combinação introdutória de passos feitos em pé), footwork (parte da dança em que o b-boys podem fazer composições de passos, incluindo movimentos de solo) e freeze (encerramento da performance com a exibição imóvel de uma posição singular). Os dançarinos podem acrescentar movimentos acrobáticos, chamados de power move. 
$\mathrm{Na}$ maioria dos casos, tratava-se de aprendizados por mimese, no sentido descrito por Bourdieu (1990) em relação às práticas esportivas. A visualização do exemplo e a tentativa de imitá-lo ganhava lugar importante. Assim, a presença e atuação dos mais experientes eram significativas, criando referências para apropriação de movimentos e memorização corpórea de gestos e sequências. Vale aventar, ademais, que o estruturar de disposições para a dança operava desde uma ambiência que extrapolava os exercícios em treino, de forma que a mimese derivava sua efetividade da imersão em outras práticas que faziam o contexto dos $b$-boys, por exemplo, as experiências relatadas por eles em capoeira, ginástica ou o próprio consumo musical e a frequência em festas.

Certa vez, em uma roda de conversa entre professores de dança e integrantes do Restinga Crew, houve um convite por parte de Jean, um dos criadores do grupo, para que o autor do presente trabalho experimentasse passos básicos. Nessa ocasião, o b-boy se postou como educador e repetia movimentos lentamente e explicava como o autor deveria proceder. Este procurou seguir suas orientações, mas o resultado parecia-lhe desconcertante. Fazia um enorme esforço de concentração para imitar o que os corpos treinados do instrutor e dos colegas (oriundos do curso de dança) pareciam fazer com muita facilidade. Tentaram passos básicos de toprock e footwork, e o autor relatou que seu corpo sinalizava que lhe faltava força e equilíbrio, fazendo-o pensar em todo o trabalho representado pela corporeidade do instrutor. Seu corpo hábil "conectava" passos de maneira fluída e iniciava as sequências coreográficas por qualquer ponto, na expressão de uma memória para além do racionalizado.

\section{A CRIAÇÃO E AS TECNOLOGIAS}

Para além e em articulação com a mimese, contudo, o trabalho individual dos b-boys nos treinos representava a busca pela construção de estilo, ou de flavour, como dizia Henrique, usando expressão corrente no meio. Alguns poderiam ser mais melódicos nos gestos, outros poderiam explorar características de elasticidade ou força. Dessa maneira, os passos receberiam variações conforme as singularidades dos dançarinos. Embora o domínio dos fundamentos fosse uma busca, a aprendizagem rigorosa dos passos não se resumia a uma realização padronizada; era associada explicitamente à construção de um jeito próprio de fruição, que singularizasse o $b$-boy com os pares.

A construção do estilo ancorava-se, ainda, em estudos. Os dançarinos despendiam horas na internet, buscando materiais (músicas, vídeos, tutoriais etc.) que lhes informassem sobre a história da "cultura", sobre eventos e manifestações de dança e sobre exibições de dançarinos de break ou outros gêneros. No caso dessas últimas, replicavam um hábito iniciado com o uso de fitas VHS pelos mais velhos e amplificavam seus acessos, conhecendo contextos de diferentes partes do globo. Afirmavam procurar materiais e inspirações na rede, de modo que um vídeo poderia ser analisado várias vezes, para que pudessem replicar um passo e, em seguida, alterá-lo compondo algo de pessoal e original.

Em uma noite bastante fria, nem todos se exercitavam no ginásio. Alguns estavam assistindo um vídeo no computador. Versava sobre a história do hip-hop e 
mostrava cenas do início dos anos 1980. Seco comentava as roupas e estilos diferentes no vídeo propositadamente sem áudio, no qual, vez ou outra, surgia algum texto em inglês. Para exemplificar o que explicava, caminhava pelo espaço representando jeitos de caminhar de $b$-boys americanos e brasileiros, tentando delimitar elementos das identidades que percebia.

Esse não era um fato isolado. Em geral, os integrantes do grupo usavam a tecnologias digitais como celulares, notebooks e tablets. Além de estudarem os passos de outros dançarinos, filmavam seus treinos para analisarem os movimentos; gravavam suas apresentações, editavam de maneira rudimentar os registros e divulgavam em redes sociais. Nesse sentido, as condições de acesso a equipamentos culturais de que dispunham os interlocutores se aproximava do afirmado por Barbosa (2013) acerca de favelas do Rio de Janeiro. Não havendo a oferta de alternativas por aparatos público-estatais, eles seguiam construindo suas experiências estéticas em atividades informais, combinando linguagens audiovisuais e técnicas informacionais na produção de estratégias de fruição, aprendizagem e socialização do que faziam.

Seus usos de recursos digitais sugeriam, ademais, que poderiam ser retomadas as ideias de Lévy (1997) acerca da noção de "ecologia cognitiva". A demonstração de disposições para navegar por um ambiente hipertextual e, a partir daí, compor acervos próprios para estudos (músicas e vídeos, sobretudo) e operar na composição de seus próprios artefatos para compartilharem em rede parecia configurar um modo preferencial de aprender, ancorado no que lhes era significativo e ambientado pelas possibilidades tecnológicas das quais conseguiam usufruir.

Os integrantes do Restinga Crew, salvo em casos de mensagens curtas em redes sociais, não faziam uso muito extensivo da escrita ou da leitura. Suas experiências de escolarização tinham garantido apenas uma apropriação elementar de tais códigos. Contudo, o uso de imagens e o acesso à internet possibilitavam novas bases de memória estendida para o que lhes interessava conhecer/pesquisar e também para o que desejavam registrar e socializar dentre suas realizações.

Pra se inventar o passo, tu faz uma pesquisa. Tu pesquisa vários vídeos de outros dançarinos pra ver a forma como eles estão fazendo aquele passo. Daí, tu tenta errar aquele passo. Depois que eu fiz ele errado, eu vou tentar fazer ele errado o tempo todo, entendeu?, pra eu criar uma identidade e as pessoas ver que eu não estou errando. Não é um erro porque eu não sei fazer, mas sim um erro porque eu quero fazer daquela forma, pra ti ter reconhecimento, entendeu? (Jean - Jan/2014)

Além disso, sentindo-se a descartabilidade do que se acessa ou disponibiliza, dada a intensidade da circulação de informações e a dificuldade de se garantir autoria, quando a cópia ou a adaptação de passos era corrente, a construção do estilo individual parecia ser uma busca vivida como necessária nessa ambiência. Assim, retorna-se ao flavour, condição para distinção entre os pares e possibilidade para ancorar a singularização diante da produção massiva e recorrente de variações sobre o tema (de que eles próprios eram coautores). 


\section{A ESTÉTICA}

No curso de tal análise, vale considerar também a relação dos b-boys com sua prática pela potência da produção artística. Frequentemente, os interlocutores narravam o break como aquele gênero de dança cuja flexibilidade e abertura à composição mereceria destaque. Característica que podia observar nos demais elementos do hip-hop, quando via as mixagens feitas por DJs ou, em outro exemplo, as composições de rappers.

A sensibilidade ${ }^{8}$ que professavam se dirigia especialmente à interação com aqueles que se dispunham a partilhar momentos de dança com eles. Afirmavam sua abertura em nome das possibilidades de aprendizagem recíproca. Segundo os dançarinos, mesmo aquele que ainda não sabe poderia contribuir com um jeito de andar ou com alguma ideia sobre a qual não tinham pensado. A experiência estética a que se propunham parecia se associar a uma disposição ética, aberta a interações naquilo que os move e, nesse sentido, respeitosa do que o outro sabe e pode dispor para a partilha desde o que lhe é peculiar.

Afirmavam que poderiam compor sequências coreográficas com passos de diversos tipos de danças, práticas esportivas ou acontecimentos cotidianos. Nesse contexto, afirmavam a necessidade de sensibilidade ao que o entorno lhes apresentasse. Acredita-se que falavam do que Pereira (2012) chama de uma "atitude estética", como uma "atitude desinteressada, uma abertura, uma disponibilidade não para o acontecimento em si, para os efeitos que ele produz na percepção" (Pereira, 2012, p. 186). Tal condição de suscetibilidade seria, para o autor, a potencializadora da experiência estética que instiga a criação.

Assim, pode-se dizer que fruíam as músicas deixando que o corpo construísse o caminho no gingar de movimentos e, dessa forma, tinham ideias para sequências de passos. Seco contou, certa vez, como teria imaginado a proposta da Feeling Gaúcho, a coreografia mais conhecida do grupo na cena de Porto Alegre. Estava a escutar músicas de madrugada e, quando organizava seu acervo de canções gauchescas, teve a intuição de compor passos de break ao som destas. Em seguida, telefonou para Henrique e falou da inspiração. Naquele momento, não era mais que isso, uma epifania. Depois, para a composição da coreografia, Henrique disse que deixou que a música escolhida lhe instigasse sobre que passos dispor em sequência.

...a produção artística é um ensaiar, um proceder através de propostas e esboços, interrogações pacientes da matéria. Mas esta aventura criativa tem um ponto de referência e um termo de comparação. $\mathrm{O}$ artista procede por tentativas, mas a sua tentativa é guiada pela obra tal como deverá ser, algo que, sob a forma de um apelo, e de uma exigência intrínseca à formação, orienta o processo produtivo: o ensaiar dispõe, portanto, de um critério, indefinível mas muito sólido: o pressentimento do resultado... o adivinhar da forma. (Eco, 2008, p. 18)

8 Para "estética", considera-se, aqui, a acepção relacionada ao termo grego aisthesis, que designa percepção, sensibilidade. 
Disseram que não haveria uma narrativa (em sentido estrito) na sequência que compuseram. Mas a tomada de posição era explícita: a possibilidade de integração, de que fruíssem juntos aqueles que, costumeiramente, viviam separados. Indicia-se então, algo não necessariamente racionalizado, mas que compunha uma criação passível de interação e mobilização; algo intuitivo, performático e espetacular que condensa certa interpretação de cenário e reflexividade e convida a plateia a partilhar desta última.

\section{INDIVIDUAÇÕES EM NARRATIVA}

O conjunto das dinâmicas narradas sinaliza para um jogo relacional em que a pertença ao coletivo se erige em articulação às possibilidades de singularização individual, de forma que a prática em breakdance conecta-se recursivamente com o processo estrutural de singularização analisado por Martuccelli (2007). As oportunidades para fruição, aprendizagem e composição de estilos particulares engendravam desafios, ao mesmo tempo que as atividades e os laços construídos pela crew configuravam suportes desde os quais os sujeitos podiam conquistar reconhecimento social e significar a existência de suas individualidades. Vale, agora, adentrar mais nessa análise, tomando casos específicos dessa experiência.

Para efeito das análises propostas aqui, foram escolhidos dois integrantes para narrativa de seus percursos biográficos. Não há como explorar todas as singularidades em questão. As análises que seguem visam realçar diferentes processos de individuação e, neste ínterim, distintas formas de aproximação às dinâmicas reflexivas da crew. A escolha considerou tempo de permanência e posição no grupo, idade e tipo de ocupação preponderante no cotidiano: Henrique, líder da creww, participava das atividades desde seu início e trabalhava como "oficineiro"; e Heitor, dançarino havia dois anos, ainda considerado um dos mais recentes na formação do grupo, era estudante de ensino médio.

\section{HENRIQUE, ENTRE A SOCIABILIDADE E A ASTÚCIA}

Entre os b-boys do Restinga Crew, Henrique era reconhecido como a referência para contatos, agendamentos e também para a organização das iniciativas do grupo, dos ensaios aos eventos na cidade ${ }^{10}$. À época da interlocução, tinha 29 anos e vivia na Restinga, onde crescera. Tinha três filhos de seu primeiro relacionamento e, então, namorava uma $b$-girl da crewu.

Ele contou que, no início da infância, sua família residia em uma parte mais abastada do bairro e vivia sob condições econômicas estáveis. Henrique o afirmava

9 Denominação utilizada por eles para designar sua atividade como facilitador em oficinas de aprendizagem em elementos do hip-hop.

10 Durante o período em que o grupo foi acompanhado para a pesquisa, percebeu-se que frequentemente se dedicavam a organizar eventos de dança no bairro e na cidade, acessando pontos culturais reconhecidos de Porto Alegre (Casa de Cultura Mário Quintana, Usina do Gasômetro etc.). As programações associavam rachas de break, oficinas e festas, e, em alguns casos, tratava-se de etapas (classificatórias) de campeonatos de circuito nacional. 
citando que o pai possuía emprego, que tinham empregada e costumavam fazer doações no Natal. No entanto, quando o pai perdera o vínculo formal de trabalho, foi preciso que se mudassem para uma casa cedida pela avó. E, então, logo após a mudança, veio a separação de seus pais.

Não muito tempo depois, por volta dos seis anos de idade, sua mãe o deixou sob cuidados da avó, em outra casa. Segundo narrava, sua mãe trabalhava durante o dia e, de quinta a domingo, envolvia-se com festas e discotecagem. Assim, permanecia sozinho em casa por várias horas, o que preocupava os familiares. Em sua narrativa, as referências para proteção e apoio eram sua avó, com quem crescera, e seu irmão mais velho, com quem aprendera a dançar. Contudo, mantinha contato regulares com os pais e frequentava suas casas regularmente: uma composição que se aproxima às dinâmicas familiares e de circulação de crianças narradas por Fonseca (2004).

A casa da minha mãe sempre tinha muita gente. Todos os amigos do meu irmão, que dançava. Tinha amigos da minha mãe. E sempre tinha música. Minha mãe tinha um estúdio de som. Faziam festa, discotecava. Eu era pequeno e ficava sentado no sofá e eu via eles se preparando. Era som alto, minha mãe dançando. (Maio/2014)

Enfatizou que, logo cedo, teve contato com a música, com a dança e com a circulação de amigos em casa. Contudo, apesar dos convites do irmão para que praticasse dança em suas oficinas, resistiu a começar. Dizia ser "gordo" e sentir-se constrangido. Já escutava rap desde criança e desejava destacar-se cantando. Porém, quando um amigo de sua idade, então com aproximadamente 15 anos, decidiu aprender break e o convidou para acompanhá-lo, encorajou-se a frequentar os treinos no CECORES.

Enquanto narrava seu itinerário na aprendizagem da dança, fez uma das poucas menções à escola. À custa de certo esforço, conseguiu aprender os passos, mudando sua condição física inclusive. À época, soube da existência de uma oficina de dança na escola pública onde estudava. Passou a integrar as aulas, assessorando o educador no ensino dos colegas. Conforme contava, o espaço escolar teria sido, assim, o primeiro cenário onde obtivera significativo reconhecimento público pelo que fazia; o lugar vivenciado com timidez, especialmente pela condição física, passou a local de destaque entre os colegas.

Coincide com a imersão e destaque na dança o nascimento do primeiro dos três filhos (todos frutos do primeiro namoro). Junto a isso, veio a necessidade urgente de trabalhar, o que lhe conduziu a uma série de atividades informais e precárias e ao abreviamento da trajetória escolar, encerrada no primeiro ano do ensino médio. Em relação a esta última, Henrique não parecia demonstrar vínculos significativos e se resumia a mencionar casos associados à sociabilidade com colegas e/ou de visibilização pela dança.

Contando com o apoio de familiares para suprir a subsistência dos filhos, e apesar da condição precarizada, Henrique permaneceu praticando dança e, conforme assinalava, frequentava rigorosamente os treinos do grupo ainda em formação. 
Os colegas da crew frequentavam sua casa regularmente e permaneciam até tarde da noite, assistindo vídeos e conversando sobre suas atividades; em alguns casos, chegaram a residir com ele por algum tempo ${ }^{11}$. A participação em eventos e campeonatos se intensificava nesse momento.

Logo após a constituição do Restinga Creww, em 2003, o b-boy conseguiu a primeira inserção como oficineiro de dança em um projeto assistencial. Em depoimento bastante reflexivo, a relação com a prática é narrada em diferentes fases.

Quando eu comecei a dançar eu queria desenvolver os movimentos que eu via nas fitas cassete, entendeu? Eu queria usar mais os meus braços, porque eu não gostava daquela coisa de colocar as costas no chão. $\mathrm{O}$ segundo interesse porque eu queria dançar: um comecei a ficar muito conhecido e dava muito 'pé quente' com as gurias. Como eu era muito gordinho, eu no colégio não tinha essas coisas de ter namorada. E o terceiro momento, eu queria ganhar mais dinheiro com o que eu gostava de fazer. Esse momento foi que me levou a elaborar coreografia, procurar conhecimento, participar de campeonato. (Maio/2014)

O depoimento de Henrique traz uma elaboração narrativa de diferentes momentos em sua trajetória, sinalizando para intentos continuados de distinção articulados aos contextos relacionais em que se situava. Seus relatos indiciavam que a dança de rua, na qual contava com aportes da socialização familiar, foi o espaço onde construiu distinção (não vislumbrado da mesma forma na escola ou em ambientes de trabalho). A prática da dança gestada nas iniciativas do hip-hop se constituiu como a arena em que encontrou, articuladamente, "suportes" e "provas" que oportunizassem reconhecimento social e a elaboração de um projeto reflexivo.

A referência aqui é à participação individual e grupal nos campeonatos e/ou na organização de eventos, mas também às inserções logradas e táticas produzidas por Henrique. As atividades como oficineiro eram sua principal fonte de renda na época dos diálogos deste estudo. Ademais, posicionava-se procurando replicar e ampliar as vivências de sociabilidade, fruição e visibilização que experenciara em seu itinerário. Nesse sentido, ele contava que um de seus objetivos em trabalhar como educador residia em divulgar o Restinga Crew e conquistar novos dançarinos para o grupo.

Eu pensava em dar aula de dança porque eu queria ter mais dançarinos, entendeu?! Ir pros lugares e trazer mais pessoas para o Restinga Crew. Ampliar a rede

11 Segundo Henrique, o relacionamento com a mãe de seus filhos teria terminado em parte por conta da intensidade com que se envolvia com a dança e os amigos, fazendo de sua casa um espaço frequentemente tomado pelas dinâmicas do grupo. Destaca-se esse fato porque, na brevidade das narrativas apresentadas, considera-se oportuno lembrar das tensões que percorreram os itinerários contados, evitando a impressão de que se constituíam como biografias lineares e projetadas. Trata-se mais de um olhar retrospectivo do itinerário, que se formara numa série de tentativas, variações de intensidade e vínculos, descontinuidades e táticas. 
e hoje a gente não tem gente só da Restinga. Aonde ia o Restinga Crew eu sempre dava um jeitinho de colocar os meus alunos para apresentar. (Maio/2014)

O jovem contou, certa vez, que teria chegado à prática educativa por conta das necessidades e oportunidades que surgiram. Então, dadas as circunstâncias, teria criado um jeito de trabalhar. Nas oficinas conduzidas por ele no contraturno das aulas de uma escola pública municipal ${ }^{12}$, percebia que procurava instaurar um programa de trabalho orientado às festividades escolares. Ensinava passos básicos para que, compondo uma sequência, os alunos pudessem apresentar em eventos ${ }^{13}$.

O b-boy não gozava do status de professor, era educador ou oficineiro. Contava que não havia reunião com professores, e, além disso, as oficinas que realizava não eram articuladas a conteúdos curriculares ou a práticas de docentes nas disciplinas. Indiciava-se certa hierarquização entre capitais culturais, e o trabalho que realizava parecia instrumentalizado sob o intento de oferecer alternativas de ampliação do tempo de permanência na escola.

Se a instituição escolar agregava o break como uma técnica apenas, ou tinha o intuito de atender aos alunos nominados como "agitados" ou "problemáticos", a despeito da "cultura" a que se vinculava a dança para o $b$-boy, ele não parecia tomar isso em consideração. Seu trabalho se prestava a garantir (financeiramente, sobretudo) a vivência daquilo pelo que sua identidade preferencial mais clamava. Não foi percebida identificação de Henrique com a dinâmica escolar e, como sinalizado acima, ele se ocupava mais de fazer da atividade como educador o espaço para suas iniciativas.

De toda forma, sua tomada de posição não impede a observação dos logros alcançados a partir do capital cultural acumulado em suas práticas informais de dança, fruição e sociabilidade em contexto de periferia.

Conservando en primer los cambios históricos y los inevitables efectos del diferencial del posicionamento social entre los actores, las pruebas permiten justamente dar cuenta de la manera en que lo individuos son producidos y se producen. (Martuccelli, 2007, p. 112)

12 A oportunidade de trabalhar em escolas públicas (e não só em programas assistenciais) chegou para Henrique após a implementação de políticas governamentais de integralização da educação. A Secretaria Municipal de Educação viabiliza projetos educativos no contraturno escolar com recursos federais (pelo Programa Mais Educação) e, também, por convênios com organizações não governamentais atuantes na cidade. À época da pesquisa, o interlocutor era contratado por fundação pertencente a um clube de futebol local. Essa era sua principal ocupação. Eventualmente, fazia atividades para complementação de renda ou para arrecadar fundos que viabilizassem a participação (sua e/ou de colega da crew) em eventos de dança.

13 Além do programa de trabalho mencionado, observava que Henrique procurava criar um ambiente de partilha com os alunos, a exemplo do que vivenciava nos treinos da crew. Dizia, além disso, que desejava servir como exemplo e apoiar os educandos a ter mais "concentração e foco" em relação a seus objetivos, evitando o envolvimento com "coisas ruins" (referindo práticas violentas e/ou criminalidade), aproximando-se da discursividade de ativistas do hip-hop ouvidos nas incursões de pesquisa. 


\section{HEITOR, A DANÇA E A PERGUNTA POR UM PROJETO}

Diferentemente da maioria de seus colegas de grupo, Heitor não cresceu em um bairro de elevada precarização das condições de vida. Segundo relatou, vivia até então no bairro Aberta dos Morros, em área semirrural vizinha à Restinga. Tinha 17 anos, era filho único e morava com os pais. Sua mãe trabalhava em casa e tinha concluído a quinta série escolar; seu pai concluíra a terceira série do ensino fundamental e trabalhava desde os oito anos de idade em atividades de jardinagem e construção civil.

Sua infância teria transcorrido naquele espaço. Costumava brincar com os amigos na rua em frente à sua casa e dizia ser a localidade onde residia um local tranquilo, sem os riscos de um "bairro como a Restinga". A carreira escolar começou na educação infantil e, a partir dos dez anos de idade, passou a acompanhar seu pai nas atividades de trabalho. Na parede da sala, figurava uma foto sua de criança, vestindo toga: "foi a formatura da creche", como disse ao narrar o forte incentivo dos pais aos estudos.

À distinção de seus colegas, Heitor integrava um núcleo familiar que não passara por mudanças de composição ao longo de sua curta trajetória. Nesse cenário relativamente estável, o estímulo ao envolvimento precoce com práticas laborais e o incentivo aos estudos parecem ter materializado exemplo das "razões do improvável", no sentido definido por Lahire (1997) ao elencar aspectos que poderiam levar filhos de grupos populares ao sucesso escolar, mesmo quando o reduzido capital cultural não o ensejasse.

Meu pai sempre exigiu que, embora eu trabalhasse, sempre fosse minha educação em primeiro lugar, minha mãe também nunca me deixou eu faltar. Teve um ano que eu não faltei nenhum dia de aula. Então, eu sempre tentei ser o mais assíduo possível nas aulas. Faltei uma vez só pra fazer uma apresentação da crew com o Renato Borghetti. (Mar/2014)

Heitor concluiu o ensino médio sem reprovações e pretendia cursar faculdade. Vale considerar, aqui, que a relação com a carreira escolar, mesmo articulada a projeções pessoais, não parecia significar adesão aos propósitos escolares. Demonstrava disposições orientadas à construção de um caminho próprio de independência, de "fazer por si", gestadas com a moral familiar operada pela inserção precoce ao trabalho e à escolarização. Assim, embora tenha atuado em conformidade com a instituição, a produção de sentidos em relação a ela apresentava nuances.

Por volta dos 10 anos de idade, decidiu frequentar um Centro de Tradições Gaúchas (CTG) por desejo de experimentar algo diferente das tarefas de sua rotina. Sua demanda foi atendida pela família, que passou a frequentar também as atividades do Centro. Ele relatou que seus pais participavam apenas para acompanhá-lo e incentivá-lo. Tão logo Heitor deixou o CTG, eles também pararam de frequentar o local.

O único contato que eu tinha com a cultura hip-hop era a música, né?. O rap que eu sempre gostei, Eu conheci a dança sem sair daqui, né?, por alguns amigos 
meus que começaram a dançar. Um deles dançava freestyle e fazia capoeira e, aí nessa da capoeira, ele conheceu um rapaz que treinava no grupo Restinga Crew. Com quatorze anos, eu comecei a ir nos treinos assiduamente. (Mar/2014)

Seguia vinculado ao CTG quando amigos the ensinaram alguns passos de break. Acessou os treinos do Restinga Crew por intermédio de sua rede de sociabilidade e quando passou a frequentá-lo, o grupo já era bastante conhecido na cena hip-hop de Porto Alegre. Afirmou em entrevista que a dança representava, de início, uma espécie de compensação da rotina que tinha: além de frequentar a escola e auxiliar seu pai, ele trabalhava em diversas atividades informais que garantissem rendimentos e uma relativa independência financeira.

Eu só estudava e trabalhava, então era um, um robô! Então a dança me tirou disso né, porque não interessa o que acontece da porta do treino pra fora; a partir do momento que tu ouve uma música que tu gosta teu sentimento já é outro, tua cabeça já é outra, tu quer dançar e não interessa o resto, sabe?

E não seria um hobby... Ah quarta-feira eu vou sair com a minha namorada, então não vou dançar. Não, não tem como, sabe?! É uma coisa que não consigo mais faltar, por algum motivo assim. Uma coisa que tu já precisa daquilo, sabe? (Mar/2014)

Segundo sua narrativa, estar entre os $b$-boys representava a possibilidade de fruição, reconhecimento e, consonante com seu modo de "fazer por si", uma forma de experienciar autonomia. Ademais, foi o meio pelo qual a vivência do espaço urbano se reconfigurou: com amigos, passou a circular por diferentes partes da cidade e, algumas vezes, a viajar para participar de eventos; também com eles, aprendera a caminhar pelas ruas, identificando e evitando potenciais situações de risco.

Porém, a pertença de Heitor à dança precisa ser colocada em perspectiva. Ele afirmava como prioridade as projeções de continuidade de sua carreira escolar e de inserção profissional. A vinculação ao grupo e ao break não era apresentada como temporária, mas também não gozava de centralidade. Em vez de se colocar o compromisso de escolher, ele tendia a apostar na possibilidade de conciliar interesses e pertenças múltiplos.

Retomando os argumentos de Vieira (2012), considera-se que seu processo de individuação configurou-se por pelos menos três elementos: na socialização oportunizada pela família, que, por seus meios, parece ter reconhecido logo cedo sua condição de indivíduo com autonomia; em complementaridade e contraste, na liberdade de fruição e no protagonismo construídos com os amigos, em relativo distanciamento dos pais; e na assunção da relação institucional educação-trabalho, na qual vinha atuando com disciplina e êxito, para a narratividade de um projeto individual.

Eles [os colegas de crew] já passaram mais necessidade do que eu, né. Mas eles viveram muito mais intensamente dança do que eu também, né? Quando eles se apegaram naquilo, eles realmente se jogaram! Eu tenho um controle muito grande em torno das outras coisas que eu quero, né. Não quero só dançar pelo resto da vida. (Mar/2014) 
Assim, se Henrique fez seu caminho de individuação desde as possibilidades construídas na prática do break, logrando, depois, inserções em outros locus, Heitor concebia projeções mais próximas a arenas institucionais, conforme o espaço de possibilidades que se lhe apresentava. No entanto, buscava também articular suas pertenças e manter viva a vinculação à dança e ao grupo, que considerava visceral e significativa em sua ainda curta existência.

\section{CONSIDERAÇÕES FINAIS}

A narrativa sobre as dinâmicas instauradas coletivamente nos ensaios do Restinga Crew e sobre as trajetórias de dois dos b-boys que integravam o grupo trouxe argumentos sobre as possibilidades de individuação, procurando caracterizá-las conforme os sujeitos participavam em seus espaços de possíveis, em semelhança ao que contam Leão e Carrano (2013) sobre o “jovem Milton”.

Procurou-se sinalizar que os dançarinos construíam espaços para singularizar práticas e estilos e, entre os mais experientes, logravam acumular capitais culturais. Estes lhes oportunizaram ocupações profissionais concernentes ao que apreciavam fazer, ampliando os espaços de ação onde podiam tomar posição. Aqui, pode-se considerar que, pela prática da dança, encontraram espaço de construção de autonomia e ampliaram suas possibilidades de independência, tomando aqui a problematização apresentada por Pappámikail (2012).

Em que pese as condições econômicas e culturais adversas das localidades de origem dos interlocutores desta pesquisa, a expressão do hip-hop garantiu redes de sociabilidade e de reciprocidade propícias à produção de projetos de distinção individuais, incluindo-se aí as condições de subsistência ${ }^{14}$. Contudo, a articulação entre individuação e autonomia não prescindia de laços institucionais e se organizava na integração de âmbitos institucionalizados e redes informais operadas pelos sujeitos em seus percursos.

Os jovens do Restinga Crew pareciam ter consigo uma prática reflexiva de maneira intensa e regular. E a dança, tomada em suas alusões simbólicas a guerras e/ou a batalhas entre gangues, ou nas composições com elementos percebidos no cotidiano, traz um convite à contemplação da realidade, para "devolvê-la" aos pares

14 Aqui, cabe uma ressalva. As práticas do hip-hop em Porto Alegre, conforme pode-se observar, sofrem de certa perda de sua capacidade mobilizatória. As iniciativas da "cultura' parecem estar setorizadas e muitos daqueles que eram lideranças alocados em posições institucionalizadas (como produtores ou assessores políticos), sem que, com isso, o movimento tenha conquistado uma organização política que lhe garantisse condições satisfatórias de disputa por recursos públicos. Além disso, o rap já não tem o mesmo apelo nas comunidades de periferia que tinha nos anos 1990 e início dos 2000. Tais considerações são para refletir sobre a posição de grupos como o Restinga Crew nas disputas de poder. Embora tivessem conhecimento valorizado e fossem consultados eventualmente em função disso (por pesquisadores, jornalistas, empresas, etc.), esse quadro não muda a vulnerabilidade de sua condição material. Embora os b-boys logrem ocupações mais bem remuneradas em alguns casos, estas são instáveis. Se há potencialidades à individuação, as possibilidades de independência material ainda são restritas. 
e ao público em versão espetacularizada. Além disso, os treinos e os rachas, especialmente, são momentos que promovem disposições reflexivas ao lançar os indivíduos em diálogos gestuais que, mais que a imitação, exigem resposta provocativa. $\mathrm{O}$ break traz um componente interpretativo sem que isso signifique racionalização necessariamente, ao modo de uma reflexividade estética (mimética), que nos remete a uma comunidade onde se partilha uma "hermenêutica de reapropriação" (Lash, 2012).

Essa hermenêutica da reapropriação, diferentemente dos mestres (e dos artífices contemporâneos) da dúvida, não vai destruir continuamente as fundações, mas vai tentar manter abertas as bases ontológicas do estar-no-mundo comunal [...] buscará designar um conjunto estabelecido de bens substantivos como base de qualquer tipo de ética comunal [...] não estará cronicamente em dúvida faustiana, em busca de "significados transcendentais", não irá cronicamente adiar e negar a significação. (Lash, 2012, p. 224)

Tal condição não contraria necessariamente e pode ser complementar à reflexividade cognitiva realizada por ativistas do $h i p$ - $h o p$ quando elaboram narrativas sobre a história da "cultura". Mas uma condição que guarda a singularidade de não se encerrar obrigatoriamente no enunciado, mantendo sociabilidade e ensejando aprendizagens e fruição nos alinhavos da conotação. É considerada a hipótese de que, como uma forma de expressão representativa das fragmentações e descontinuidades do cotidiano urbano, as sequências coreográficas levam às plateias da crew movimentos cuja inter-relação não seria linear e racionalizada, mas não deixava de comunicar sensações concernentes às vivências na urbe. Em analogia, assistir às apresentações era como assistir cenas de um filme em ritmo acelerado, ou fixar os olhos na paisagem movediça avistada pela janela de um ônibus.

A dança praticada pelos interlocutores constituía-se intuitivamente para um mostrar ao outro; expressão do que se percebe e sente. Parecia uma bricolagem espetacularizada, devolvendo-nos o cotidiano urbano multiforme e intensificado que produzimos atualmente. Embora não seja narrativo em sentido estrito, não deixa de dizer "vejam, divirtam-se vendo o que é possível realizar; sintam o que temos a manifestar assistindo o que conseguimos fazer"; por ícones múltiplos, passíveis de interpretação hipertextual de quem o assiste, o break comunica por sintonias.

\section{REFERÊNCIAS}

Barbosa, J. L. Pesquisa de hábitos e práticas culturais de jovens residentes em cinco favelas cariocas. In: (Org.). Solos culturais. Rio de Janeiro: Observatório das Favelas, 2013. p. 165-194.

BECK, U. A reinvenção da política: rumo a uma teoria da modernização reflexiva. In: Beck, U; Giddens, A.; Lash, S. Modernização reflexiva. São Paulo: UNESP, 2012. p. 11-88.

Bourdieu, P. Programa para uma sociologia do esporte. In: . Coisas ditas. São Paulo: Brasiliense, 1990. p. 207-220. 
Camarano, A. A. Transição para a vida adulta ou vida adulta em transição? Rio de Janeiro: Ipea, 2006.

CAstells, M. A transformação do mundo na sociedade em rede. In: Redes de indignação e esperança: movimentos sociais na era da internet. Rio de Janeiro: Zahar, 2013. p. 157-174.

Eco, U. A definição de arte. Lisboa: Edições 70, 2008.

Fonseca, C. Família, fofoca e honra: etnografia de relações de gênero e violência em grupos populares. Porto Alegre: Editora da UFRGS, 2004.

Heitor. Entrevista [mar. 2014]. Entrevistador: Leandro R. Pinheiro. Porto Alegre, 2014. 1 arquivo .mp3 (40 min.). A entrevista na íntegra encontra-se transcrita no acervo 'Enunciar cotidianos' - Faculdade de Educação/Universidade Federal do Rio Grande do Sul, 22p.

Henrique. Entrevista [set. 2013]. Entrevistador: Leandro R. Pinheiro. Porto Alegre, 2013. 1 arquivo .mp3 (60 min.). A entrevista na íntegra encontra-se transcrita no acervo 'Enunciar cotidianos' - Faculdade de Educação/Universidade Federal do Rio Grande do Sul, 31p.

Herschmann, M. Espetacularização e alta visibilidade: A politização da cultura hip-hop no Brasil contemporâneo. In: Freire, J.; Herschman, M. (Orgs.). Comunicação, cultura e consumo: a (des)construção do espetáculo contemporâneo. Rio de Janeiro: EPapers, 2005. p. 153-168.

Jean. Entrevista [jan. 2014]. Entrevistador: Leandro R. Pinheiro. Porto Alegre, 2014. 1 arquivo .mp3 (32 min.). A entrevista na íntegra encontra-se transcrita no acervo 'Enunciar cotidianos' - Faculdade de Educação/Universidade Federal do Rio Grande do Sul, 18p.

Jovchelovitch, S. Entrevista narrativa. In: Bauer, M. (Org.). Pesquisa qualitativa com texto, imagem e som. Petrópolis: Vozes, 2002. p. 90-113.

LAHire, B. Sucesso escolar nos meios populares: as razões do improvável. São Paulo: Ática, 1997. LAsh, S. A reflexividade e seus duplos: estrutura, estética e comunidade. In: BECK, U.; Giddens, A.; Lash, S. Modernização reflexiva. São Paulo: Editora da UNESP, 2012. p. 167-258.

LeÃo, G.; Carrano, P. O jovem Milton: a individuação entre a igreja e a educação social. Educação E̊ Realidade, v. 38, n. 3, p. 895-914, jul.-set. 2013.

LÉvy, P. As tecnologias da inteligência: o futuro do pensamento na era da informática. São Paulo: 34, 1997.

Martuccelli, D. Cambio de rumbo: la sociedade a escala Del individuo. Santiago: LOM, 2007.

Melucci, A. A invenção do presente. Petrópolis: Vozes, 2001. . O jogo do eu. São Leopoldo: Editora UNISINOS, 2004.

Nunes, M. Restinga:memórias dos bairros. Porto Alegre: PMPA, 1990.

ObservaPoa. Restinga: dados gerais. Disponível em: <http://portoalegreemanalise. procempa.com.br/?regiao=93_0_0>. Acesso em: 24 mar. 2015. 
Oliveira, P. Para além do Hip Hop: juventude, cidadania e movimento social. Motrivivência, ano XVI, n. 23, p. 61-80, dez. 2004.

PAPPÁmiKaIL,L.Juventude(s), autonomia e sociologia: redefinindo conceitos transversais a partir do debate acerca das transições para a vida adulta. In: DAYreLL, J. et al.(Orgs.). Familia, escola e juventude: olhares cruzados Brasil-Portugal. Belo Horizonte: Editora da UFMG, 2012. p. 372-393.

Pardue, D. Desempenhando atitude: uma imposição de espaço e gênero pelos hip hoppers brasileiros. Revista de Antropologia, v. 51, n. 2, p. 519-546, 2008.

Pereira, M. V. O limiar da experiência estética: contribuições para pensar um percurso de subjetivação. Pro-posições, Campinas, n. 1 (67), p. 183-195, jan.-abr. 2012.

Reguillo, R. Culturas juveniles: formas políticas del desencanto. Buenos Aires: SigloVeintinuo, 2012.

Rekziegel, A. C. Dança de rua: lazer e cultura jovem na Restinga. Dissertação (Mestrado) - Universidade Federal do Rio Grande do Sul, Porto Alegre, 2004.

SEco. Entrevista [dez. 2013]. Entrevistador: Leandro R. Pinheiro. Porto Alegre, 2013. 1 arquivo .mp3 (40 min.). A entrevista na íntegra encontra-se transcrita no acervo 'Enunciar cotidianos' - Faculdade de Educação/Universidade Federal do Rio Grande do Sul, 22p.

VIEIRA, M. M. Incerteza e individuação: escolarização como processo de construção biográfica. In: DAYrell, J. et al. (Orgs.). Família, escola e juventude: olhares cruzados Brasil-Portugal. Belo Horizonte: Editora da UFMG, 2012. p. 276-297.

\section{SOBRE O AUTOR}

Leandro Rogério Pinheiro é doutor em educação pela Universidade do Vale do Rio dos Sinos (UNISINOS). Professor da Universidade Federal do Rio Grande do Sul (UFRGS).

E-mail: leandro_pinheiro@hotmail.com

Recebido em 25 de maio de 2015

Aprovado em 22 de outubro de 2015 